\title{
A Long Term Evaluation of the Japanese Medical Payment System for Cataract Surgeries: Did the Medical Policy Reduce the Long Hospital Stay in Japan?
}

\author{
Kazumitsu Nawata ${ }^{1,2}$, Koichi Kawabuchi ${ }^{3}$ \\ ${ }^{1}$ Graduate School of Engineering, University of Tokyo, Tokyo, Japan \\ ${ }^{2}$ Department of Economics and Related Studies, University of York, York, UK \\ ${ }^{3}$ Graduate School of Medical and Dental Sciences, Tokyo Medical and Dental University, Tokyo, Japan \\ Email: nawata@tmi.t.u-tokyo.ac.jp, kawabuchi.hce@tmd.ac.jp
}

Received 30 May 2016; accepted 22 June 2016; published 27 June 2016

Copyright @ 2016 by authors and Scientific Research Publishing Inc.

This work is licensed under the Creative Commons Attribution International License (CC BY).

http://creativecommons.org/licenses/by/4.0/

(c) (i) Open Access

\begin{abstract}
In this paper, we conducted a long term survey of the cataract surgeries. The sample period was about 7 years, from July 2005 to March 2012. We evaluated the effects of three revisions of the medical payment system that were done in 2006, 2008 and 2010. For the analysis, the Box-Cox transformation model and Hausman test using Nawata's estimator were used for the length of stay (LOS) in hospitals, and the ordinary least squares method was used for the non-inclusive (mainly payments for surgeries) payments. We analyzed a dataset of 51,054 patients obtained from 60 hospitals (Hp1-60) where more than 300 one-eye cataract surgeries were performed during the period. For the LOS, we found that only the 2008 revision had significant impact on shortening the LOS but the other two did not. We also found very large differences among hospitals even after eliminating effects of patients' characteristics and type of principle diseases as previous studies. For non-inclusive payments 2006 and 2008 revisions had significant impacts and the differences among hospitals were much smaller than those of the LOS.
\end{abstract}

\section{Keywords}

DPC/PDPS, Inclusive Payment System, Cataract, Length of Stay (LOS), Box-Cox Transformation Model, Hausman Test

How to cite this paper: Nawata, K. and Kawabuchi, K. (2016) A Long Term Evaluation of the Japanese Medical Payment System for Cataract Surgeries: Did the Medical Policy Reduce the Long Hospital Stay in Japan? Health, 8, 905-919. 


\section{Introduction}

A medical inclusive payment system based on the Diagnosis Procedure Combination (DPC), called the DPC/ PDPS (DPC/per diem payment system) [1], was introduced in 2003 for 82 special functioning hospitals. From April 2004, general hospitals could join the DPC/PDPS. Under the DPC/PDPS, the medical payments consist of two different parts. One is inclusive payments based on the DPC codes and Length of Stay (LOS) in hospitals (hereafter, inclusive payments), and the other is non-inclusive payments based on the conventional fee-for-service system (hereafter, non-inclusive payments). In principle, the first one mainly covers the "hospital fee" that is necessary to operate the hospital, and the second covers the "doctoral fee" for medical treatments such as surgeries. For the inclusive payments, three periods, Periods I and II and the Specific Hospitalization Period, and per diem payments are determined by DPC codes, and per diem payments become smaller as the LOS becomes longer. If the LOS exceeds the Specific Hospitalization Period, the inclusive payment goes back to a conventional fee-for-service base. For details of the DPC and DPC/PDPS, see Nawata et al. [2]. The joining DPC/ PDPS has not been obligatory, and a hospital can freely choose to join the DPC/PDPS or not if it satisfies necessary conditions [3]. However, according to Central Social Insurance Medical Council [4], as of April 2014, 1585 hospitals had joined the DPC/PDPS and additional 278 were preparing to join the system (hereafter, DPC hospitals). The DPC hospitals comprised $24.9 \%$ of the 7483 general hospitals and had 511,439 beds, which accounted $57.0 \%$ of the total $(897,749)$ beds in all general hospitals, and the likelihood of DPC participation increased with hospital size. The DPC hospitals are required to computerize their medical information, it has become possible to analyze a large scale dataset which includes information of many patients, various diseases and treatments from many hospitals. The DPC/PDPS has been revised by every second year after 2004. Therefore, evaluations of revisions are very important for the efficient use of medical resources in Japan.

In this paper, we evaluate the effects of the 2006, 2008 and 2010 revisions of the medical payment system on the Length of Stay (LOS) and non-inclusive payments of cataract surgeries (Since actual inclusive payments to hospitals may be different for identical treatments, we analyzed the LOS rather than the inclusive payments). The sample period was about 7 years, from July 2005 to March 2012. In case of cataract surgeries, the portions of the inclusive and non-inclusive payments are about one-third and two-thirds, respectively. According to the survey of the Ministry of Health, Labour and Welfare [5], 79,192 cataract surgeries were done for 59,318 cases and their direct costs were 8.75 billion yen in June 2013. This means that nearly one million cataract surgeries and over 100 billion yen are spent annually. Although the effect of the single revision on the LOS was evaluated [6], analyses of long term evaluation of the revisions on the LOS and the non-inclusive payments have not been studied.

Among OECD countries, most cataract surgeries were performed on a day-case basis, without staying hospital after surgery (hereafter, day surgery), due to advances of medical technology and better anasthetics [7]. Percentages of day surgeries of many OECD countries exceeded 95\% in 2011 [7]. In the cataract surgeries, "a dirty natural lens is removed, and then replaced by an artificial lens, called an intraocular lens (IOL)” [8]. The surgery will typically take less than 15 minutes per eye [9]. Trivedi et al. [10] reported that the length of hospital of cataract surgery could be reduced to an average of 3 hours and 37 minutes. Atalla et al. [11] surveyed data of 671 cataract patients in an Australian hospital. 226 (33.4\%) patients were hospitalized overnight. But they conclude that "many patients who are hospitalized overnight could be safely treated as day cases". Fedorowicz, Lawrence and Guttie [12] also reported that there was no significant difference in outcome or risk of postoperative complications between day surgeries and surgeries with hospitalization. Even in an old study, Ingram et al. [13] reported that only 13\% patients preferred to stay hospital after the surgeries among 501 cataract cases.

On the other hand, the long LOS for cataract surgeries in Japan was been very long. In our original dataset, there were 56,364 one-eye cataract surgery (just one eye was operated in a single hospitalization) cases. Among one-eye surgeries, only $1.7 \%$ of patients were day surgeries and average length of stay (ALOS) was 3.82 days. The LOS shows a fat tailed distribution on the right hand side.

Therefore, for the analysis of the LOS, the Box-Cox [14] transformation model (hereafter, BC model) is used as previous studies. The maximum likelihood estimator under the normality assumption (hereafter, BC MLE) is used for the estimation of the BC model. The BC MLE is generally inconsistent unless the "small $\sigma$ " assumption described in Bickel and Doksum [15] and the error terms are independent and identically distributed (i.i.d.) random variables. Nawata [16] proposed semi-parametric estimators of the BC models. Using Nawata's estimator, we first test the BC MLE to determine whether or not we can use the BC MLE for the estimation of the BC 
model by the Hausman [17] test.

\section{Estimators and Tests of the BC Model}

\subsection{BC Model}

Suppose that LOS of patient $\mathrm{t}$ is given by the BC model:

$$
\begin{gathered}
z_{t}=x_{t}^{\prime} \beta+u_{t}, y_{t} \geq 0, \\
z_{t}= \begin{cases}\frac{y_{t}^{\lambda}-1}{\lambda}, & \text { if } \lambda \neq 0,2, \cdots, T, \\
\log \left(y_{t}\right), & \text { if } \lambda=0,\end{cases}
\end{gathered}
$$

where $y_{t}$ is the LOS, $x_{t}$ and $\beta$ are the k-th dimensional vectors of the explanatory variables and coefficients, respectively, and $\lambda$ is the transformation parameter. The likelihood function under the normality assumptions is given by

$$
\log L(\theta)=\sum_{t} \log f_{t}(\theta), \text { and } \log f_{t}(\theta)=\log \phi\left\{\left(z_{t}-x_{t}^{\prime} \beta\right) / \sigma\right\}-\log \sigma+(\lambda-1) \log y_{t},
$$

where $\theta^{\prime}=\left(\lambda, \beta^{\prime}, \sigma^{2}\right), \phi$ is the probability density function of the standard normal assumption and $\sigma^{2}$ is the variance of $u_{t}$. We can obtain the BC MLE is obtained by maximizing Let $\theta_{0}^{\prime}=\left(\lambda_{0}, \beta_{0}^{\prime}, \sigma_{0}^{2}\right)$ be the true parameter value of $\theta$. The BC MLE is generally inconsistent. However, if the error terms are i.i.d. random variables (hereafter, i.i.d. assumption) and the "small $\sigma$ " assumption given by $\lambda_{0} \sigma_{0} /\left(1+\lambda_{0} x_{t}^{\prime} \beta_{0}\right) \rightarrow 0$ (practically, $P\left[y_{t}<0\right]$ is small enough under the normality assumption), the BC MLE can be a consistent estimator, and "small $\sigma$ " asymptotics [15] of the BC MLE $\hat{\theta}_{B C}^{\prime}=\left(\hat{\lambda}_{B C}, \hat{\beta}_{B C}^{\prime}, \hat{\sigma}_{B C}^{2}\right)$ are given by

$$
\sqrt{T}\left(\hat{\theta}_{B C}-\theta_{0}\right) \rightarrow N\left[0, A^{-1} B\left(A^{\prime}\right)^{-1}\right],
$$

where $A=-\frac{1}{T} E\left[\left.\frac{\partial^{2} \log L}{\partial \theta \partial \theta^{\prime}}\right|_{\theta_{0}}\right]$, and $B=E\left[\left.\left.\frac{\partial \log f_{t}}{\partial \theta}\right|_{\theta_{0}} \frac{\partial \log f_{t}}{\partial \theta^{\prime}}\right|_{\theta_{0}}\right]$.

\subsection{N-Estimator}

Nawata [16] considered the roots of the equations,

$$
\begin{gathered}
G_{T}(\theta)=\sum_{t}\left[-\frac{1}{\sigma^{2} \lambda}\left[\left\{\frac{\log \left(\lambda x_{t}^{\prime} \beta+1\right)}{\lambda}+\frac{z_{t}-x_{t}^{\prime} \beta}{\lambda x_{t}^{\prime} \beta+1}\right\} y_{t}^{\lambda}-z_{t}\right]\left(z_{t}-x_{t}^{\prime} \beta\right)\right. \\
\left.+\frac{1}{\lambda} \log \left(\lambda x_{t}^{\prime} \beta+1\right)+\frac{z-x_{t}^{\prime} \beta}{\lambda x_{t}^{\prime} \beta+1}\right] \equiv \sum_{t} g_{t}(\theta) \\
\frac{\partial \log L}{\partial \beta}=0, \text { and } \frac{\partial \log L}{\partial \sigma^{2}}=0 .
\end{gathered}
$$

When the first- and third-moments of $u_{t}$ are zero, the estimator given by Equation (4) is consistent. The asymptotic distribution of the estimator $\hat{\theta}_{N}^{\prime}=\left(\lambda_{N}, \beta_{N}^{\prime}, \sigma_{N}^{2}\right)$ (hereafter, N-estimator) becomes

$$
\sqrt{T}\left(\hat{\theta}_{N}-\theta_{0}\right) \rightarrow N\left[0, C^{-1} D\left(C^{\prime}\right)^{-1}\right],
$$

where $C=-E\left[\left.\frac{\partial \ell_{t}(\theta)}{\partial \theta^{\prime}}\right|_{\theta_{0}}\right], \quad D=E\left[\ell_{t}\left(\theta_{0}\right) \ell_{t}\left(\theta_{0}\right)^{\prime}\right], \ell_{t}(\theta)^{\prime}=\left[g_{t}(\theta), \xi_{t}(\theta)^{\prime}, \varsigma_{t}(\theta)\right]$,

$\xi_{t}(\theta)=\frac{1}{\sigma^{2}} x_{t}\left(z_{t}-x_{t}^{\prime} \beta\right)$, and $\varsigma_{t}(\theta)=\frac{\left(z_{t}-x_{t}^{\prime} \beta\right)-\sigma^{2}}{2 \sigma^{2}}$. 


\subsection{Hausman Test for the BC Model}

The BC MLE is consistent under the i.i.d. and "small $\sigma$ " assumptions. Therefore, we can test the null hypothesis consisting of these assumptions by the Hausman test using the N-estimator. Under the null hypothesis, we get,

$$
\sqrt{T}\left(\hat{\lambda}_{N}-\hat{\lambda}_{B C}\right) \rightarrow N\left(0, \delta_{1}\right),
$$

where $\delta_{1}=(1,1)$ element of $\left(A^{-1}-C^{-1}\right) B\left(A^{-1}-C^{-1}\right)^{\prime}$. Let $\hat{\delta}_{1}$ be the estimator of $\delta_{1}$ and $t=\sqrt{T}\left(\hat{\lambda}_{N}-\hat{\lambda}_{B C}\right) / \sqrt{\hat{\delta}_{1}}$. Since $t \rightarrow N(0,1)$ under the null hypothesis, we can test using $t$ as the test statistic [5]. Note that we cannot use two or more parameters in the Hausman test in this case [18]. We can use the BC MLE if the null hypothesis is accepted. Nawata and Kawabuchi [19] considered a further test when the null hypothesis is accepted. But the null hypothesis consists of compounded assumptions, and the further test is not necessary if the null hypothesis is accepted. Note that we need other estimators and tests if the null hypothesis is rejected [19]-[22].

\section{Data and Summary of the Revisions for Cataract Surgeries}

In this study, we use data from the Section of Health Care Economics of Tokyo Medical and Dental University. The data were collected from over 100 Japanese hospitals from July 2005 to March 2012. For each patient, gender, age, dates of hospitalization, medical payment amounts, DPC code, names of principle disease and disease that caused hospitalization, International Classification of Diseases 10th revision (ICD-10) code of the WHO for the diseases, up to four surgeries, information of comorbidities and complications, placement after hospitalization and other information of patients were available. Our original dataset contained information of 92,766 cataract patients and there were 56,364 one-eye cataract surgery cases. Although National Eye Institute [8] recommended to a 4 - 8 week interval between surgeries when a patient needs cataract surgeries for both eyes, both eyes are operated in a single hospitalization (hereafter, two-eye surgeries) to a large number of patients in Japan. 36.6\% underwent two-eye surgeries in our dataset (For the rest of the patients, either DPC codes were not available or no surgeries were done).

As mentioned earlier, we analyzed patients who underwent one-eye cataract operations. The DPC codes, per diem payments by the LOS and Specific Hospitalization Periods for these patients are given in Table 1. (In Japan, medical payments are measured by points and 10 yen per point are paid to hospitals.) In all three revisions, three periods determined by the DPC/PDPS became shorter and per diem payments became less. There was a clear intention of the Japanese policy makers to reduce the LOS for cataract surgeries.

The dataset of 51,054 patients from 60 hospitals which had more than 300 cataract surgeries was used in the analysis. Table 2 shows the average length of stay (ALOS) by hospital. The ALOS of all patients was 3.76 days

\section{Table 1. DPC codes and inclusive payments for cataract patients ${ }^{+}$.}

\begin{tabular}{|c|c|c|c|c|c|c|}
\hline Periods & DPC Code & \multicolumn{4}{|c|}{ LOS and Per Diem Payments (points) } & $\begin{array}{c}\text { Specific } \\
\text { Hospitalization }\end{array}$ \\
\hline $2005-2006$ & 0201103x01x000 & $\begin{array}{c}\text { LOS } \\
\text { Per Diem Payment }\end{array}$ & $\begin{array}{c}\text { 1st-3rd } \\
2509\end{array}$ & $\begin{array}{l}\text { 4th-6th } \\
1855\end{array}$ & $\begin{array}{c}\text { 7th-10th } \\
1577\end{array}$ & 10 \\
\hline $2006-2008$ & 020110xx97x0x & $\begin{array}{c}\text { LOS } \\
\text { Per Diem Payment }\end{array}$ & $\begin{array}{c}\text { 1st-2nd } \\
2418\end{array}$ & $\begin{array}{c}\text { 3rd-4th } \\
1787\end{array}$ & $\begin{array}{c}\text { 5th-8th } \\
1519\end{array}$ & 8 \\
\hline $2008-2010$ & 020110xx97x0x0 & $\begin{array}{c}\text { LOS } \\
\text { Per Diem Payment }\end{array}$ & $\begin{array}{c}1 \mathrm{st} \\
2363\end{array}$ & $\begin{array}{c}\text { 2nd-3rd } \\
1900\end{array}$ & $\begin{array}{c}\text { 4th-7th } \\
1615\end{array}$ & 7 \\
\hline 2010-2012 & 020110xx97xxx0 & $\begin{array}{c}\text { LOS } \\
\text { Per Diem Payment }\end{array}$ & $\begin{array}{c}\text { 1st-2nd } \\
2237\end{array}$ & $\begin{array}{c}\text { 3rd-4th } \\
1627\end{array}$ & $\begin{array}{c}\text { 4th-6th } \\
1464\end{array}$ & 6 \\
\hline
\end{tabular}

\footnotetext{
${ }^{+}$: The DPC/PDPS is revised in April of every second year.
} 
Table 2. Distribution of LOS by hospitals.

\begin{tabular}{|c|c|c|c|c|c|c|c|}
\hline \multirow{2}{*}{ Hospital } & \multirow{2}{*}{ No. of patients } & \multicolumn{2}{|c|}{ LOS } & \multirow{2}{*}{ Hospital } & \multirow{2}{*}{$\begin{array}{l}\text { No. of } \\
\text { patients }\end{array}$} & \multicolumn{2}{|c|}{ LOS } \\
\hline & & ALOS & S.D. & & & ALOS & S.D. \\
\hline Hр1 & 684 & 4.14 & 1.31 & Нp31 & 357 & 3.19 & 0.84 \\
\hline Hр2 & 493 & 2.39 & 0.95 & Нp32 & 305 & 3.36 & 1.33 \\
\hline Hр3 & 383 & 6.20 & 1.90 & Нp33 & 902 & 3.22 & 0.90 \\
\hline Hр4 & 658 & 5.16 & 1.21 & Нp34 & 755 & 2.92 & 0.87 \\
\hline Hp5 & 969 & 3.30 & 1.35 & Нp35 & 739 & 3.18 & 1.48 \\
\hline Hp6 & 448 & 3.44 & 0.96 & Нр36 & 342 & 4.60 & 2.12 \\
\hline Hp7 & 684 & 3.47 & 1.22 & Нp37 & 1719 & 4.09 & 1.47 \\
\hline Hp8 & 691 & 3.00 & 0.67 & Нр38 & 642 & 6.17 & 1.49 \\
\hline Hр9 & 884 & 3.64 & 1.52 & Нр39 & 1498 & 5.84 & 1.85 \\
\hline Нp10 & 496 & 2.99 & 0.13 & Нр40 & 1534 & 3.12 & 1.56 \\
\hline Нp11 & 2442 & 2.85 & 0.83 & Нp41 & 830 & 2.71 & 1.16 \\
\hline Hp12 & 436 & 3.43 & 1.88 & Нp42 & 1342 & 4.61 & 1.82 \\
\hline Нр13 & 556 & 3.67 & 1.53 & Нp43 & 2,877 & 3.45 & 1.41 \\
\hline Hр14 & 604 & 4.78 & 1.88 & Нp44 & 1048 & 4.19 & 2.31 \\
\hline Hp15 & 570 & 2.13 & 0.59 & Нp45 & 312 & 3.48 & 3.57 \\
\hline Нp16 & 1088 & 3.07 & 0.45 & Нр46 & 592 & 4.05 & 2.35 \\
\hline Hр17 & 1251 & 3.31 & 0.83 & Нp47 & 1145 & 3.89 & 0.97 \\
\hline Нp18 & 2124 & 4.00 & 0.26 & Нр48 & 1539 & 4.25 & 1.91 \\
\hline Нp19 & 466 & 2.99 & 0.08 & Нp49 & 1365 & 3.83 & 1.85 \\
\hline Нр20 & 560 & 2.07 & 0.47 & Нp50 & 595 & 5.44 & 3.10 \\
\hline Нp21 & 1236 & 3.15 & 0.61 & Нp51 & 355 & 3.08 & 0.65 \\
\hline Hр22 & 445 & 6.84 & 1.12 & Hp52 & 719 & 4.39 & 1.55 \\
\hline Нp23 & 326 & 3.97 & 2.14 & Нp53 & 1008 & 4.30 & 1.25 \\
\hline Нp24 & 893 & 3.08 & 0.74 & Hp54 & 232 & 3.32 & 0.71 \\
\hline Нp25 & 703 & 4.04 & 0.56 & Hp55 & 406 & 4.63 & 1.38 \\
\hline Нp26 & 1863 & 3.76 & 0.81 & Нp56 & 363 & 6.66 & 2.35 \\
\hline Нp27 & 1632 & 3.55 & 1.04 & Hp57 & 549 & 5.32 & 2.53 \\
\hline Нp28 & 744 & 3.05 & 0.41 & Hp58 & 373 & 4.72 & 1.33 \\
\hline Нр29 & 683 & 3.46 & 0.64 & Hр59 & 601 & 2.35 & 1.31 \\
\hline Нр30 & 355 & 3.35 & 0.93 & Нp60 & 402 & 4.05 & 0.55 \\
\hline All & 51,054 & 3.76 & 1.64 & & & & \\
\hline
\end{tabular}

with standard deviation (S.D.) of 1.64 days. The maximum and minimum ALOS among hospitals were 6.84 (Hp22) and 2.07 (Hp20) days, respectively. The difference was 4.77 days and there were large differences among hospitals. Table 3 shows the total, inclusive and non-inclusive payments per patient to hospitals. The average total cost was 229,491 yen with S.D. of 45,602 yen, the average inclusive payment was 74,886 yen with S.D. of 36,209 yen, and the average non-inclusive payment was 154,606 yen with S.D. of 22,578 yen. The noninclusive payment composed of about two-thirds and inclusive cost was just one third. However, S.D. of inclusive payments is much bigger than that of the non-inclusive payments, and a large portion of the difference of 
Table 3. Distribution of medical payments per patient by hospitals (yen).

\begin{tabular}{|c|c|c|c|c|c|c|c|}
\hline Hospital & Total & Inclusive & Non-inclusive & Hospital & Total & Inclusive & Non-inclusive \\
\hline HP1 & 242,199 & 83,748 & 158,451 & HР31 & 221,323 & 63,981 & 157,341 \\
\hline HP2 & 204,729 & 50,934 & 153,795 & HP32 & 222,677 & 64,084 & 158,593 \\
\hline HP3 & 275,758 & 115,179 & 160,579 & НР33 & 223,553 & 62,508 & 161,045 \\
\hline HP4 & 262,723 & 99,871 & 162,851 & НР34 & 208,510 & 63,358 & 145,152 \\
\hline HP5 & 219,202 & 67,852 & 151,350 & HP35 & 212,968 & 60,918 & 152,049 \\
\hline HP6 & 229,684 & 69,486 & 160,198 & НР36 & 243,604 & 82,411 & 161,193 \\
\hline HP7 & 226,709 & 70,517 & 156,192 & HР37 & 240,610 & 81,521 & 159,089 \\
\hline HP8 & 216,297 & 61,282 & 155,015 & НР38 & 273,376 & 115,719 & 157,657 \\
\hline HP9 & 220,770 & 63,162 & 157,608 & HР39 & 272,105 & 112,470 & 159,635 \\
\hline HP10 & 220,308 & 68,075 & 152,234 & HP40 & 222,369 & 65,550 & 156,819 \\
\hline HP11 & 216,198 & 60,095 & 156,103 & HP41 & 201,569 & 56,355 & 145,214 \\
\hline HP12 & 236,829 & 72,106 & 164,723 & HP42 & 246,145 & 89,179 & 156,966 \\
\hline HP13 & 228,235 & 78,297 & 149,937 & HР43 & 221,168 & 68,954 & 152,214 \\
\hline HP14 & 248,177 & 96,540 & 151,637 & HP44 & 213,577 & 63,491 & 150,086 \\
\hline HP15 & 196,332 & 46,225 & 150,107 & HP45 & 241,764 & 80,912 & 160,852 \\
\hline HP16 & 215,142 & 63,749 & 151,393 & HP46 & 225,939 & 73,496 & 152,443 \\
\hline HP17 & 226,144 & 73,160 & 152,984 & HP47 & 244,372 & 82,581 & 161,792 \\
\hline HP18 & 219,451 & 73,708 & 145,743 & HP48 & 227,587 & 75,657 & 151,930 \\
\hline HP19 & 217,456 & 62,814 & 154,642 & HР49 & 231,591 & 80,034 & 151,556 \\
\hline HP20 & 200,137 & 45,448 & 154,688 & HP50 & 226,552 & 76,105 & 150,447 \\
\hline HP21 & 218,871 & 65,303 & 153,568 & HP51 & 278,392 & 108,986 & 169,406 \\
\hline HP22 & 284,528 & 127,994 & 156,534 & HP52 & 220,903 & 64,592 & 156,311 \\
\hline HP23 & 237,239 & 81,536 & 155,702 & HP53 & 241,561 & 79,298 & 162,263 \\
\hline HP24 & 216,553 & 63,829 & 152,724 & HP54 & 246,518 & 84,819 & 161,700 \\
\hline HP25 & 229,000 & 78,978 & 150,022 & HP55 & 249,042 & 90,844 & 158,198 \\
\hline HP26 & 231,262 & 76,243 & 155,018 & HP56 & 287,360 & 129,554 & 157,805 \\
\hline HP27 & 231,262 & 76,243 & 155,018 & HP57 & 250,477 & 95,791 & 154,686 \\
\hline HP28 & 220,438 & 62,688 & 157,750 & HP58 & 238,497 & 82,588 & 155,909 \\
\hline HP29 & 220,863 & 68,050 & 152,812 & HP59 & 194,205 & 50,433 & 143,772 \\
\hline HР30 & 221,134 & 68,856 & 152,278 & HP60 & 229,125 & 79,575 & 149,550 \\
\hline All & 229,491 & 74,886 & 154,606 & & & & \\
\hline
\end{tabular}

the medical payments caused by the inclusive payments. The maximum total, inclusive and non-inclusive payments among hospitals were 287,360 (Hp56), 129,554 (Hp56) and 164,406 (Hp51) yen, respectively. The minimum total, inclusive and non-inclusive payments among hospitals were 194,205 (Hp59), 45,448 (Hp20) and 143,772 (Hp59) yen, respectively. The differences were 93,155, 84,106 and 25,634 yen, respectively. The differences of the inclusive payments among hospitals were much larger than those of the non-inclusive payments.

\section{Results of Estimation}

\subsection{Analysis of the LOS by the BC Mode}

Figure 1 shows the distribution of LOS of one-eye cataract surgeries. Since the distribution has a fat tail on the 


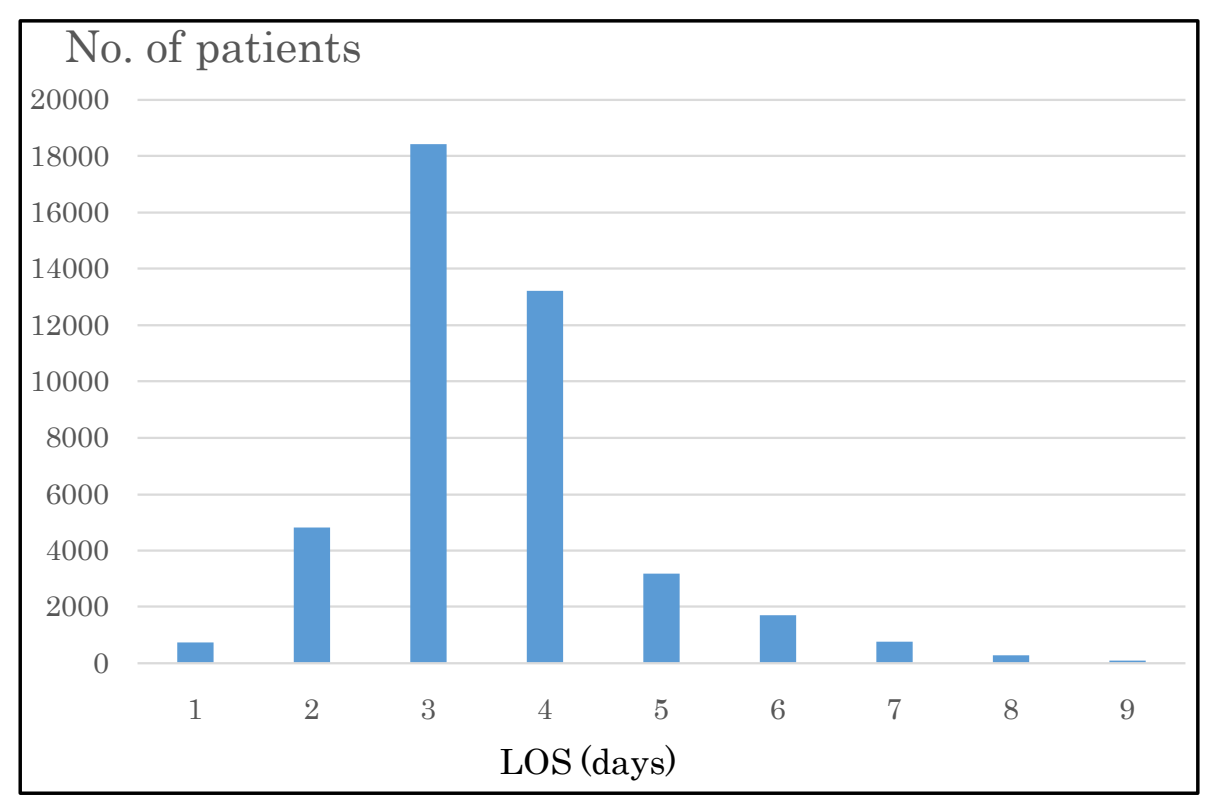

Figure 1. Distribution of the LOS.

right side, we use the BC model described in Section 3. For the analysis of LOS, it is necessary to consider the characteristics of the patients and the types of principal diseases. We also consider the effects of advances and improvements of cataract surgery technologies. The explanatory variables used in the BC model were shown in Table 4. As the basic information of patients, gender and age were considered. Under the Japanese mandatory public insurance system, the direct payments of patients was $10 \%$ for age 70 or over and $30 \%$ for younger than 70 in the sample period. So, the Over 70 dummy was added. Comorbidity (number of comorbidities), Complication (number of complications), and Emergency, Outpatient and Home dummies were used for representing conditions of patients. The Summer and Winter dummies were used to evaluate seasonal effects. To evaluate the effects of three revisions of the DPC/PDS, which is one the major purposes of the paper, we used three (i.e., After 2006, 2008 and 2010) dummies. For evaluation of advances of medical technology for cataract surgeries, Trend was added. Since we are analyzing a long term effect (7 years), the trend might have been changed and we added the squared term of trend. The payment goes back to the conventional fee-for-service base if the LOS exceeds the Specific Hospitalization Period, and per-diem payment is not reduced after the Specific Hospitalization Period. Over Period dummy was used to evaluate this effects. Thirteen ICD-10 dummies (base of these dummies was H25.0), were used to represent the influences of principal diseases. We used sixty hospital dummies were used to evaluate the influences of the hospital directly and a constant term was not included in the model

As a result, $x_{i j}^{\prime} \beta$ of Equation (1) became

$$
\begin{aligned}
x_{i j}^{\prime} \beta= & \beta_{1} \text { Female }+\beta_{2} \text { Age }+\beta_{3} \text { Over } 70+\beta_{4} \text { Comorbidity }+\beta_{5} \text { Complication } \\
& +\beta_{6} \text { Emergency }+\beta_{7} \text { Outpatient }+\beta_{8} \text { Home }+\beta_{9} \text { Summer }+\beta_{10} \text { Winter } \\
& +\beta_{11} \text { After } 2006+\beta_{12} \text { After } 2008+\beta_{13} \text { After } 2010+\beta_{14} \text { Trend }+\beta_{15}(\text { trend })^{2} \\
& +\beta_{16} \text { Over Period }+\sum \beta_{j} j \text {-th ICD } 10 \text { dummy }+\sum \beta_{k} \text { Hp } k \text { dummy. }
\end{aligned}
$$

The result of the estimation is given in Table 5. The estimates of the transformation parameters were $\hat{\lambda}_{B C}=0.2489$ and $\hat{\lambda}_{N}=0.2402$. The estimate of $\sqrt{V\left(\hat{\lambda}_{B C}-\hat{\lambda}_{N}\right)}=0.0129$ and we got $t=0.6733$. Therefore, the i.i.d. and "small $\sigma$ " assumptions were accepted at the 5\% significance level and we can use the BC MLE in this analysis.

The estimate of Female dummy and Age were positive and significant at 1\% level. Although the estimate of Over 70 were positive but not significant at the $5 \%$. The LOS became longer for females and for older patients, but we did not admit the effect of lower payments for patients age 70 or over in this study. The estimates of 
Table 4. Definitions and summary of explanatory variables.

\begin{tabular}{|c|c|c|}
\hline Variable & Definition & Summary of 51054 patients \\
\hline Female & Dummy variable; 1 : female, 0 : otherwise & $1: 28,745$ \\
\hline Age & Age of patient & mean: 73.4, S.D.: 10.2 \\
\hline Over 70 & Dummy variable; 1 : Age 70 or over, 0 : otherwise & 1: 36,293 \\
\hline Comorbidity & Number of comorbidities, & $\begin{array}{l}\text { 0: } 2814,1: 11,938,2: 5220, \\
\text { 3: } 2724,4: 3068\end{array}$ \\
\hline Complication & Number of complications & $\begin{array}{c}\text { 0: 33,993, 1: } 10,992,2: 5087 \\
\text { 3: } 772 ; 4: 210\end{array}$ \\
\hline Emergency & Dummy variable; 1: Emergency hospitalization, 0: otherwise & 1: 9021 \\
\hline Outpatient & Dummy variable; 1 : Outpatient, 0 : otherwise & 1: 48,267 \\
\hline Home & Dummy variable; 1 : return to home, 0 : otherwise & 1: 46,003 \\
\hline Summer & Dummy variable; 1 : summer ${ }^{+}, 0$ : otherwise & 1: 12,532 \\
\hline Winter & Dummy variable; 1 : winter ${ }^{++}, 0$ : otherwise & 1: 10,147 \\
\hline After 2006 & Dummy variable; 1: After April 2006. 0: otherwise & 1: 50,006 \\
\hline After 2008 & Dummy variable; 1: After April 2008, 0: otherwise & 1: 41,656 \\
\hline After 2010 & Dummy variable; 1: After April 2010, 0: otherwise & 1: 23,005 \\
\hline Trend & No. of months from April 2005 & months from April 2005 \\
\hline Over Period & $\begin{array}{c}\text { Dummy variable; 1: LOS exceeds the Specification } \\
\text { Hospitalization Period, 0: otherwise }\end{array}$ & 1: 1098 \\
\hline \multicolumn{3}{|l|}{ ICD 10 dummies } \\
\hline $\mathrm{H} 250^{+++}$ & senile incipient cataract & 24,022 patients \\
\hline $\mathrm{H} 251$ & 1: senile nuclear cataract, 0 otherwise & 1: 7672 \\
\hline H252 & 1: senile cataract, morgagnian-type, 0 other wise & 1: 535 \\
\hline $\mathrm{H} 258$ & 1: other senile cataract, 0 : otherwise & 1: 2395 \\
\hline H259 & 1: senile cataract, unspecified, 0 : other wise & 1: 5398 \\
\hline $\mathrm{H} 260$ & 1: infantile and juvenile cataract, 0 : otherwise & 1: 2828 \\
\hline $\mathrm{H} 262$ & 1: complicated cataract, 0 : otherwise & 1: 161 \\
\hline H263 & 1: drug-induced cataract, 0 : otherwise & 1: 119 \\
\hline H264 & 1: After-cataract, 0 : otherwise & 1: 50 \\
\hline H268 & 1: other specified cataract, 0 : otherwise & 1: 520 \\
\hline H269 & 1: unspecified cataract, 0 otherwise & 1: 5938 \\
\hline $\mathrm{H} 27$ & 1: Other disorders of lens (H271 \& H272), 0: otherwise & 1: 171 \\
\hline H28 & 1: diabetic cataract (H281 \& H282), 0: otherwise & 1: 733 \\
\hline \multicolumn{3}{|c|}{ Hospital Dummies } \\
\hline Hр i & 1: Hospital i; 0: otherwise & \\
\hline
\end{tabular}

${ }^{+}$Summer: July and August, ${ }^{++}$Winter: December to February, ${ }^{+++}$: base of ICD10 dummies.

Comorbidity and Complication were positive and significant at the $1 \%$ and $5 \%$ levels, and comorbidities and complications made LOS longer as expected. Although the estimate of Emergency dummy was not significant, estimates of Outpatient and Home dummies were negative, positive and significant at the $1 \%$ level. It is reasonable the LOS becomes shorter if a patient is an outpatient before hospitalization since the hospital is be able to 
Table 5. Results of estimation of the BC model for LOS by the BC MLE.

\begin{tabular}{|c|c|c|c|c|c|c|c|}
\hline Variable & Coefficient & Std. Error & t-Statistic & Variable & Coefficient & Std. Error & t-Statistic \\
\hline lambda & 0.2489 & 0.0011 & $224.03^{* *}$ & HP16 & 1.4905 & 0.0288 & $51.71^{* *}$ \\
\hline Female & 0.0164 & 0.0029 & $5.5810^{* *}$ & HP17 & 1.5679 & 0.0292 & $53.76^{* *}$ \\
\hline Age & 0.001512 & 0.000239 & $6.3264^{* *}$ & HP18 & 1.7921 & 0.0284 & $63.12^{* *}$ \\
\hline Over 70 & 0.0100 & 0.0052 & 1.9381 & HP19 & 1.4739 & 0.0283 & $52.02^{* *}$ \\
\hline Comorbidity & 0.0132 & 0.0016 & $8.3719^{* *}$ & HP20 & 1.0074 & 0.0299 & $33.74^{* *}$ \\
\hline Complication & 0.0067 & 0.0033 & $2.0168^{*}$ & HP21 & 1.4409 & 0.0295 & $48.77^{* *}$ \\
\hline Emergency & 0.0102 & 0.0169 & 0.6032 & HP22 & 2.1867 & 0.0358 & $61.01^{* *}$ \\
\hline Outpatient & -0.0265 & 0.0081 & $-3.2594^{* *}$ & HP23 & 1.7407 & 0.0347 & $50.23^{* *}$ \\
\hline Home & 0.0100 & 0.0036 & $2.7644^{* *}$ & HP24 & 1.4356 & 0.0290 & $49.43^{* *}$ \\
\hline Winter & -0.0058 & 0.0038 & -1.5223 & HP25 & 1.8517 & 0.0285 & $64.91^{* *}$ \\
\hline Summer & -0.0027 & 0.0036 & -0.7374 & HP26 & 1.7214 & 0.0288 & $59.77^{* *}$ \\
\hline After 2006 & -0.0012 & 0.0246 & -0.0484 & HP27 & 1.6169 & 0.0283 & $57.06^{* *}$ \\
\hline After 2008 & -0.0527 & 0.0190 & $-2.7821^{* *}$ & HP28 & 1.4743 & 0.0292 & $50.51^{* *}$ \\
\hline After 2010 & -0.0023 & 0.0065 & -0.3504 & HP29 & 1.6666 & 0.0296 & $56.27^{* *}$ \\
\hline Trend & -0.00708 & 0.00094 & $-7.5117^{* *}$ & НР30 & 1.5463 & 0.0320 & $48.39^{* *}$ \\
\hline (Trend) $)^{2}$ & 0.0000312 & 0.0000083 & $3.7772^{* *}$ & HP31 & 1.4814 & 0.0337 & $43.97^{* *}$ \\
\hline Over Period & 1.2167 & 0.0211 & $57.64^{* *}$ & HP32 & 1.5116 & 0.0335 & $45.09^{* *}$ \\
\hline H251 & -0.0267 & 0.0068 & $-3.9450^{* *}$ & HP33 & 1.4857 & 0.0295 & $50.41^{* *}$ \\
\hline H252 & 0.1085 & 0.0169 & $6.4203^{* *}$ & HP34 & 1.3523 & 0.0311 & $43.42^{* *}$ \\
\hline H258 & 0.0933 & 0.0091 & $10.21^{* *}$ & HP35 & 1.4227 & 0.0388 & $36.71^{* *}$ \\
\hline H259 & -0.0191 & 0.0069 & $-2.7890^{* *}$ & HР36 & 1.7679 & 0.0363 & $48.73^{* *}$ \\
\hline H260 & 0.0196 & 0.0065 & $3.0307^{* *}$ & HP37 & 1.7921 & 0.0297 & $60.35^{* *}$ \\
\hline H262 & 0.0737 & 0.0268 & $2.7514^{* *}$ & НР38 & 2.2936 & 0.0316 & $72.61^{* *}$ \\
\hline H263 & -0.0367 & 0.0335 & -1.0954 & НР39 & 2.2464 & 0.0289 & $77.67^{* *}$ \\
\hline H264 & -0.1568 & 0.0639 & $-2.4523^{*}$ & HP40 & 1.3932 & 0.0327 & $42.64^{* *}$ \\
\hline H268 & -0.1109 & 0.0285 & $-3.8909^{* *}$ & HP41 & 1.2781 & 0.0338 & $37.86^{* *}$ \\
\hline H269 & -0.0355 & 0.0062 & $-5.6832^{* *}$ & HP42 & 1.9097 & 0.0301 & $63.39^{* *}$ \\
\hline $\mathrm{H} 270$ & 0.3908 & 0.0464 & $8.4212^{* *}$ & HP43 & 1.6331 & 0.0295 & $55.31^{* *}$ \\
\hline H280 & 0.0609 & 0.0105 & $5.8055^{* *}$ & HP44 & 1.4403 & 0.0308 & $46.74^{* *}$ \\
\hline \multicolumn{2}{|c|}{ Hospital Dummies } & & & HP45 & 1.8060 & 0.0288 & $62.78^{* *}$ \\
\hline HP1 & 1.8032 & 0.0314 & $57.39^{* *}$ & HP46 & 1.5486 & 0.0350 & $44.27^{* *}$ \\
\hline HP2 & 1.1513 & 0.0312 & $36.93^{* *}$ & HP47 & 1.7011 & 0.0327 & $52.01^{* *}$ \\
\hline HP3 & 2.3402 & 0.0323 & $72.53^{* *}$ & HP48 & 1.7760 & 0.0298 & $59.53^{* *}$ \\
\hline HP4 & 2.0914 & 0.0294 & $71.13^{* *}$ & HP49 & 1.7809 & 0.0301 & $59.12^{* *}$ \\
\hline HP5 & 1.4971 & 0.0291 & $51.42^{* *}$ & HP50 & 1.7393 & 0.0289 & $60.09^{* *}$ \\
\hline
\end{tabular}




\begin{tabular}{|c|c|c|c|c|c|c|c|}
\hline \multicolumn{8}{|l|}{ Continued } \\
\hline HP6 & 1.6357 & 0.0300 & $54.55^{* *}$ & HP51 & 2.1588 & 0.0399 & $54.05^{* *}$ \\
\hline HP7 & 1.5352 & 0.0330 & $46.54^{* *}$ & HP52 & 1.4731 & 0.0294 & $50.17^{* *}$ \\
\hline HP8 & 1.4289 & 0.0295 & $48.47^{* *}$ & HP53 & 1.8671 & 0.0304 & $61.33^{* *}$ \\
\hline HP9 & 1.6613 & 0.0313 & $53.11^{* *}$ & HP54 & 1.9114 & 0.0296 & $64.50^{* *}$ \\
\hline HP10 & 1.3586 & 0.0256 & $53.11^{* *}$ & HP55 & 1.9970 & 0.0312 & $64.05^{* *}$ \\
\hline HP11 & 1.3568 & 0.0288 & $47.03^{* * *}$ & HP56 & 2.2977 & 0.0349 & $65.86^{* *}$ \\
\hline HP12 & 1.3758 & 0.0444 & $30.99^{* *}$ & HP57 & 2.0826 & 0.0331 & $62.94^{* *}$ \\
\hline HP13 & 1.5123 & 0.0334 & $45.34^{* *}$ & HP58 & 1.9887 & 0.0302 & $65.80^{* *}$ \\
\hline HP14 & 1.9567 & 0.0292 & $66.90^{* *}$ & HP59 & 1.0367 & 0.0367 & $28.26^{* *}$ \\
\hline HP15 & 1.0654 & 0.0271 & $39.27^{* *}$ & HP60 & 1.8200 & 0.0299 & $60.91^{* *}$ \\
\hline
\end{tabular}

**: Significant at the $1 \%$ level, ${ }^{*}$ :Significant at the $5 \%$ level, R2 $=0.5686$. Definitions and summaries of variables are given in Table 4.

conduct various medical checkups in advance. The result of Home dummy implied that LOS becomes shorter if patients discharged to the place other than their home, and a problem of "social hospitalization" (a patient stays at hospital without medical treatments because there is no place to go after hospitalization, for details, see Innami [23]) did not occur in cataract surgeries. Both estimates of Winter and Summer dummies were not significant at the $5 \%$ level, and the seasonal effects were not admitted. Among three dummies which evaluated effects of the revisions, that is one of the major subjects of this study, only the estimate of the 2008 dummy was significant at the 1\% level and the other two were not significant. In the 2008 revision, the Period I, the period hospitals get largest payments, was shorten to just one day. On the other hand, the Period I was extended to two days in 2010 revision. So, this might be an important factor affected the behavior of hospitals. As previously mentioned, many patients prefer shorter LOS. Therefore, shortening LOS not only reduces the medical payments but also becomes patients' benefits. The estimates of Trend and (Trend) ${ }^{2}$ were significant at the $1 \%$ level and their signs were positive and negative. This means that was the LOS became shorter but effects becomes smaller as time went. The estimate of Over Period dummy was 1.217 and its t-value was 57.648. This means the effects of the Specific Period was much larger than those of other explanatory variables. For the ICD-10 dummies, estimates of H251, H259, H268 and H269 were negative and significant at 1\% level. H264 was negative and significant at 5\% level. On the other hand, H252, H258, H262, H27 and H28 were positive and significant at 1\% level. These types of diseases affected LOS. H263 was not significant and we did not admit the effect of this type of disease.

For the estimates of the Hospital dummies, the maximum was 2.332 (Hp56) and the minimum was 1.108 (Hp5); the difference was 1.305 and was much bigger than the estimates of most of other explanatory variables. This indicated that there remained large differences among hospitals, even after eliminating the influences of variables including patient characteristics, disease types, three revisions of the DPC/PDPS, time trend, and Specific Hospitalization Period.

\subsection{Analysis of Non-Inclusive Payments}

For the analysis of non-inclusive payments per patient, $n_{-} p_{t}$, we used the ordinary least squares method. The explanatory variables are the same as the previous case and the model is given by

$$
\begin{aligned}
n_{-} p_{t}= & \beta_{1} \text { Female }+\beta_{2} \text { Age }+\beta_{3} \text { Over } 70+\beta_{4} \text { Comorbidity }+\beta_{5} \text { Complication } \\
& +\beta_{6} \text { Emergency }+\beta_{7} \text { Outpatient }+\beta_{8} \text { Home }+\beta_{9} \text { Summer }+\beta_{10} \text { Winter } \\
& +\beta_{11} \text { After } 2006+\beta_{12} \text { After } 2008+\beta_{13} \text { After } 2010+\beta_{14} \text { Trend }+\beta_{15}(\text { trend })^{2} \\
& +\beta_{16} \text { Over Period }+\sum \beta_{j} j \text {-th ICD } 10 \text { dummy }+\sum \beta_{k} \text { Hp } k \text { dummy. }
\end{aligned}
$$

We cloud not get the payment information for some patients and the dataset of 50,234 patients was used in the analysis. The results of estimation are given in Table 6. The estimate of Female dummy not significant at 5\% 
Table 6. Results of estimation of the non-inclusive payment model.

\begin{tabular}{|c|c|c|c|c|c|c|c|}
\hline Variable & Coefficient & Std. Error & t-Statistic & Variable & Coefficient & Std. Error & t-Statistic \\
\hline Female & -37 & 184 & -0.2011 & HP17 & 172,703 & 1695 & $101.91^{* *}$ \\
\hline Age & -47 & 14 & $-3.2945^{* *}$ & HP18 & 162,774 & 1628 & $99.96^{* *}$ \\
\hline Over 70 & 117 & 314 & 0.3732 & HP19 & 175,841 & 1838 & $95.65^{* *}$ \\
\hline Comorbidity & 1775 & 99 & $17.98^{* *}$ & HP20 & 168,974 & 1794 & $94.19^{* *}$ \\
\hline Complication & 3023 & 198 & $15.26^{* *}$ & HP21 & 164,883 & 1729 & $95.34^{* *}$ \\
\hline Emergency & 7081 & 864 & $8.1938^{* *}$ & HP22 & 167,219 & 1860 & $89.92^{* *}$ \\
\hline Outpatient & -1734 & 415 & $-4.1765^{* *}$ & HP23 & 174,462 & 1942 & $89.86^{* *}$ \\
\hline Home & -1944 & 372 & $-5.2212^{* *}$ & HP24 & 166,060 & 1761 & $94.32^{* *}$ \\
\hline Summer & -126 & 226 & -0.5569 & HP25 & 170,493 & 1762 & $96.74^{* *}$ \\
\hline Winter & 106 & 239 & 0.4448 & HP26 & 172,670 & 1650 & $104.62^{* *}$ \\
\hline After 2006 & $-18,467$ & 1383 & $-13.35^{* *}$ & HP27 & 169,874 & 1658 & $102.45^{* *}$ \\
\hline After 2008 & 5708 & 1003 & $5.6938^{* *}$ & HP28 & 175,816 & 1781 & $98.69^{* *}$ \\
\hline After 2010 & -427 & 419 & -1.0193 & HP29 & 171,458 & 1778 & $96.43^{* *}$ \\
\hline Trend & -82 & 52 & -1.5562 & HР30 & 163,053 & 1861 & $87.64^{* *}$ \\
\hline (Trend) $)^{2}$ & 0.819 & 0.466 & 1.7556 & HP31 & 173,870 & 1762 & $98.69^{* *}$ \\
\hline Over Period & 24,342 & 672 & $36.21^{* *}$ & HP32 & 174,103 & 1957 & $88.97^{* *}$ \\
\hline H251 & 248 & 378 & 0.6573 & HP33 & 178,968 & 1706 & $104.90^{* *}$ \\
\hline H252 & 9242 & 906 & $10.20^{* *}$ & HР34 & 161,768 & 1788 & $90.48^{* *}$ \\
\hline H258 & 3911 & 547 & $7.1551^{* *}$ & HP35 & 161,247 & 1779 & $90.66^{* *}$ \\
\hline H259 & 1158 & 401 & $2.8865^{* *}$ & HР36 & 167,078 & 1938 & $86.22^{* *}$ \\
\hline H260 & -472 & 467 & -1.0099 & HP37 & 172,139 & 1629 & $105.69^{* *}$ \\
\hline H262 & 1093 & 1667 & 0.6554 & HР38 & 170,436 & 1860 & $91.61^{* *}$ \\
\hline H263 & 925 & 1881 & 0.4920 & НР39 & 175,254 & 1583 & $110.71^{* *}$ \\
\hline H264 & $-55,152$ & 2905 & $-18.98^{* *}$ & HP40 & 176,169 & 1625 & $108.44^{* *}$ \\
\hline H268 & -757 & 1566 & -0.4834 & HP41 & 164,822 & 1762 & $93.55^{* *}$ \\
\hline H269 & 1514 & 399 & $3.7912^{* *}$ & HP42 & 174,530 & 1661 & $105.06^{* *}$ \\
\hline $\mathrm{H} 27$ & 110,127 & 1625 & $67.78^{* *}$ & HP43 & 172,022 & 1660 & $103.65^{* *}$ \\
\hline $\mathrm{H} 28$ & -2543 & 801 & $-3.1739^{* *}$ & HP44 & 168,195 & 1843 & $91.25^{* *}$ \\
\hline \multicolumn{2}{|c|}{ Hospital Dummies } & & & HP45 & 179,032 & 1629 & $109.9298^{* *}$ \\
\hline HP1 & 171,504 & 1747 & $98.17^{* *}$ & HP46 & 168,452 & 1959 & $85.99^{* *}$ \\
\hline HP2 & 172,735 & 1838 & $93.96^{* *}$ & HP47 & 177,219 & 1792 & $98.89^{* *}$ \\
\hline HP3 & 174,309 & 1867 & $93.33^{* *}$ & HP48 & 165,980 & 1707 & $97.21^{* *}$ \\
\hline HP4 & 175,869 & 1779 & $98.83^{* *}$ & HP49 & 170,322 & 1588 & $107.28^{* *}$ \\
\hline HP5 & 169,654 & 1689 & $100.39^{* *}$ & HP50 & 167,846 & 1667 & $100.69^{* *}$ \\
\hline HP6 & 179,096 & 1876 & $95.43^{* *}$ & HP51 & 183,413 & 2198 & $83.46^{* *}$ \\
\hline
\end{tabular}




\begin{tabular}{|c|c|c|c|c|c|c|c|}
\hline \multicolumn{8}{|l|}{ Continued } \\
\hline HP7 & 173,722 & 1809 & $95.99^{* *}$ & HP52 & 168,072 & 1958 & $85.85^{* *}$ \\
\hline HP8 & 169,557 & 1749 & $96.93^{* *}$ & HP53 & 176,902 & 1741 & $101.63^{* *}$ \\
\hline HP9 & 175,138 & 1713 & $102.21^{* *}$ & HP54 & 179,135 & 1724 & $103.91^{* *}$ \\
\hline HP10 & 169,494 & 1694 & $100.04^{* *}$ & HP55 & 173,405 & 1912 & $90.68^{* *}$ \\
\hline HP11 & 174,903 & 1644 & $106.33^{* *}$ & HP56 & 168,902 & 1925 & $87.76^{* *}$ \\
\hline HP12 & 182,740 & 1842 & $99.17^{* *}$ & HP57 & 170,543 & 1827 & $93.35^{* *}$ \\
\hline HP13 & 167,591 & 1860 & $90.07^{* *}$ & HP58 & 173,988 & 1,862 & $93.43^{* *}$ \\
\hline HP14 & 165,899 & 1747 & $94.94^{* *}$ & HP59 & 163,938 & 1,788 & $91.68^{* *}$ \\
\hline HP15 & 169,137 & 1757 & $96.23^{* *}$ & HP60 & 160,853 & 1,913 & $84.10^{* *}$ \\
\hline HP16 & 166,004 & 1718 & $96.60^{* *}$ & $\mathrm{R} 2$ & & 0.1969 & \\
\hline
\end{tabular}

\footnotetext{
${ }^{* *}$ : Significant at the $1 \%$ level, ${ }^{*}:$ Significant at the $5 \%$ level. Definitions and summaries of variables are given in Table 4.
}

level. Although the estimate of Age was negative and significant, Over 70 was not significant at the 5\%. The non-inclusive payment became smaller for older patients, but we did not admit the effect of lower payments for patients age 70 or over in this study. The estimates of Comorbidity and Complication were positive and significant at the $1 \%$ level, and comorbidities and complications made non-inclusive payments higher. Although the estimates of Emergency and Outpatient dummies were not significant, estimates of Outpatient and Home dummies were at the $1 \%$ level. Emergency hospitalization increased the non-inclusive payments, but a patient was an outpatient or returning home reduced the non-inclusive payments. Both estimates of Winter and Summer dummies were not significant at the $1 \%$ level, and the seasonal effects were not admitted. Among three dummies which evaluated effects of the revisions, the estimates of the 2006 and 2008 dummies were significant at the $1 \%$ level but the signs were opposite. The 2006 revision made the non-inclusive payment lower and 2008 revision made it higher. The estimates of Trend and (Trend) ${ }^{2}$ were not significant and we could not find time trends unlike the LOS case. The estimate of Over Period dummy was 24,342 and its t-value was 36.218. This means that the LOS exceeded the Specific Period Hospitalization, not only LOS but also non-inclusive payments increased by a large amount. For ICD-10 dummies, estimates of H252, H258, H259, H269 and H27 were positive and significant at 1\% level. Especially, the estimate of $\mathrm{H} 27$ was 110,127 yen and very high. This was caused by the fact there were many patients who received surgeries of vitreous bodies with cataract surgeries. On the other hand, the estimate of H264 and H28 were negative and significant at 1\% level. The value of H264 was 55,152 yen. H264 is after-cataract; that is a patient took a cataract surgery before and lens capsule becomes dirty again, and the surgery just makes the lens capsule clean. The payments for this surgery was lower than regular cataract surgeries.

For the estimates of the Hospital dummies, the maximum was 183,412 (Hp44) yen and the minimum was 160,853 yen (Hp5); the difference was 22,559 yen or $14.6 \%$ of the average non-exclusive payments. The difference was much smaller than that of the LOS.

\section{Discussion}

We found that the differences of LOS among hospitals were very large but differences of the non-inclusive payments (mainly payments related to surgeries) were relatively small. Although the types of diseases were different, we got the similar results for diabetes [19] [21]. Another question is whether the LOS and the non-inclusive payments were related or not. The correlation coefficient of the estimates of hospital dummies between the LOS and non-inclusive payment models was 0.224 and t-value for testing no correlation is 1.798 . We could not say that the LOS and the non-inclusive pay were correlated. By the three revisions, the periods determined by the DPC/PDPS were shortened and per diem payments were reduced. This means that there was a strong political implication to reduce the LOS to control the medical payments. Among three revisions, only one revision significantly reduced the LOS. The results of this study shows that the LOS did not decrease much. However, the LOS could be reduced by the efforts of hospitals. For example, Kobato et al. [24] reported that the LOS was 
reduced by introduction of proper clinical pathways.

More recently, the Ministry of Health, Labour and Welfare [25] released the Japanese medical payments reached 40 trillion yen in fiscal year 2014 (Japanese fiscal year is from April to March), this figure is expected to increase as aging the population in the future. The medical payment has become a big financial problem. As already pointed out by Nawata and Kawabuchi [21], the best answers for this problem is to treat patients more efficiently and control payments without degradation of treatments. There were large differences in ALOS among hospitals even after eliminating effects of various factors. This suggested that it might be possible for many hospitals to reduce the LOS without degradation of treatments for cataract surgeries.

In the revision of the medical payment system implemented April 2014 [26], the cataract surgery is classified under the category of the Short Stay Operation Basic Payment 3. If a hospital and a patient satisfy the required conditions, a hospital gets the same amount of payments. In cataract surgeries with lens insertion, a hospital get 270,930 yen if the LOS is 5 days or less. It is essentially same as the DRG/PPS (Diagnosis-Related Group/ Prospective Payment System) widely used in the United States and other countries ${ }^{1)}$. The numbers of diseases, hospitals and patients under this system are currently small, it will be expected to increase in the future. Therefore, evaluation of the new (DRG/PPS type) payment system is an important subject for the financial sustainability of the Japanese medical payment system.

\section{Conclusions}

In this paper, we conducted a long term survey of the cataract surgeries. The sample period was about 7 years, from July 2005 to March 2012. We evaluated the effects of three revisions of the medical payment system that were done in 2006, 2008 and 2010. About one million surgeries are performed in Japan annually. For the analysis, the Box-Cox transformation model and Hausman test using Nawata's estimator are used for the LOS, and the ordinary least squares method is used for the non-inclusive payments. To evaluate these changes, we analyzed a dataset of 51,054 patients obtained from 60 hospitals (Hp1-60) where surgeries more than 300 one-eye cataract surgeries were performed during the period. The time trend reduced the LOS but degrees of reduction became smaller.

For the analysis of the LOS, gender, age, numbers of comorbidities and complications, outpatient before hospitalization, and place to go back after hospitalization were significant variables. The time trend and squared of trend were significant and the LOS became shorter but effects became smaller as time went. For ICD-10 dummies, H264 and H28 were negative and significant. H252, H258, H262 and H27 were positive and significant. The Specific Hospitalization Period also strongly affected the non-inclusive payments. Among three dummies which evaluated effects of the revisions, only the estimate of the 2008 dummy was significant and the 2008 revision reduced the LOS but not the other two. There were large differences among estimates of the hospital dummies, indicating that there remained large differences among hospitals, even after eliminating the influences of various factors.

For the analysis of the non-exclusive payments, gender, numbers of comorbidities and complications, being an outpatient before hospitalization, place to go back after hospitalization, emergency were significant variables. The effects of time trend was not admitted in this case. For ICD-10 dummies, H252, H258, H259, H264, H269, H27 and H28 were significant variables. As the LOS case, the Specific Hospitalization Period also strongly affected the non-inclusive payment. For the effects of the revisions, 2006 and 2008 dummies were significant but the signs were opposite. The 2006 revision made the non-inclusive payment lower but 2008 revision made it higher. For the estimates of the Hospital dummies, the largest difference was 22,559 yen or $14.6 \%$ of the average non-exclusive payments. The difference was much smaller than that of the LOS.

In this study, we analyzed the LOS and medical payments for cataract surgeries. For financial sustainability of the Japanese medical system, it is necessary to evaluate other diseases. Evaluation of the Short Stay Operation Basic Payment system expanded in 2014 is also necessary. In this paper, characteristics of hospitals were not analyzed. Barbieri et al. [27] reported that the LOS of private hospitals was shorter than that of public ones. These are subjects to be studied in the future.

Note: 1) Although 10 hospitals (8 national and 2 social insurance hospitals) had adopted the DRG/PPS on a trial basis from 1998 to 2004, it was not accepted by the Japanese medical society.

\section{Acknowledgements}

The Institutional Review Boards of the University of Tokyo (number: KE12-7) and Tokyo Medical and Dental 
University (number: 839) approved the use of this dataset. An earlier version of the paper was presented at the "International Symposium on Recent Developments in Econometric Theory with Applications in Honor of Professor Takeshi Amemiya (June 20-21, 2015)" at Xiamen University in China. We would like to thank an anonymous referee and the participants of the symposium for their helpful comments. We also thank various hospitals for their sincere cooperation.

\section{References}

[1] DPC Evaluation Division, Central Social Insurance Medical Council (2010) Heisei 24 nendo kaite ni muketa DPC seido (DPC/PDPS) no taiou ni tsuite (Concerning the Procedures for the 2012 Revision of the DPC System (DPC/PDPS)). (In Japanese)

[2] Nawata, K., Ii, M., Toyama, H. and Takahashi, T. (2009) Evaluation of the Inclusive Payment System Based on the Diagnosis Procedure Combination with Respect to Cataract Operations in Japan. Health, 1, 93-103.

http://dx.doi.org/10.4236/health.2009.12016

[3] Nawata, K. and Kawabuchi, K. (2015) Evaluation of Length of Hospital Stay Joining Educational Programs for Type 2 Diabetes Mellitus Patients: Can We Control Medical Costs in Japan? Health, 7, 256-269. http://dx.doi.org/10.4236/health.2015.72030

[4] Central Social Insurance Medical Council (2014) DPC taishou hyouin Junbi hyouin no kibo (heisei 26 nen 4 gatsu 1 nichi) mikomi (Estimated Sizes of DPC Hospitals and Preparing Hospitals as of April 1st, 2014). (In Japanese)

[5] Ministry of Health, Labour and Welfare (2014) Shakai iryou shinryu koui betsu chosa hesiei 25 nendo (Social medical Surveys by Treatment Practices in Fiscal Year 2013). (In Japanese)

[6] Nawata, K. and Kawabuchi, K. (2015) An Econometric Analysis of Hospital Length of Stay for Diabetes Operations in Japan by the Box-Cox Transformation Model and Hausman Tests: Evaluation of the 2010 Revision of the Medical Payment System. Open Journal of Applied Science, 5, 559-570. http://dx.doi.org/10.4236/ojapps.2015.59054

[7] OECD (2013) Health at a Glance 2013. http://www.oecd.org/els/health-systems/Health-at-a-Glance-2013.pdf

[8] National Eye Institute (2009) Facts about Cataract. https://nei.nih.gov/health/cataract/cataract_facts

[9] Jacobs, J. and Koch, P. (2009) Your Cataract Surgery Procedure \& Operation. Medical Management Services Group. http://www.aboutcataractsurgery.com/cataract-surgery-procedure.html

[10] Trivedi, N.S., Cheah, E., Heyman, C. and Qiu, C. (2002) Reducing the Length of Hospital Stay of Cataract Surgery: One Year Experience in a HMO Setting. Anesthesiology, 96, A1137. http://dx.doi.org/10.1097/00000542-200209002-01137

[11] Atalla, M.L., Wells, K.K., Peucker, K., et al. (2000) Cataract Extraction in a Major Ophthalmic Hospital: Day-Case or Overnight Stay? Clinical and Experimental Ophthalmology, 28, 83-88. http://dx.doi.org/10.1046/j.1442-9071.2000.00277.x

[12] Fedorowicz, Z., Lawrence, D.J. and Guttie, P. (2006) A Cochrane Systematic Review Finds No Significant Difference in Outcome or Risk of Postoperative Complications between Day Care and In-patient Cataract Surgery. Saudi Medical Journal, 27, 1296-1301.

[13] Ingram, R.M., Banerjee, D., Traynar, M.J. and Thompson, R.K. (1983) Day-Case Cataract Surgeries. British Journal of Ophthalmology, 67, 278-281. http://dx.doi.org/10.1136/bjo.67.5.278

[14] Box, G.E.P. and Cox, D.R. (1964) An Analysis of Transformations. Journal Royal Statistical Society Series B, 26, 211-252.

[15] Bickel, P.J. and Doksum, K.A. (1981) An Analysis of Transformations Revisited. Journal of American Statistical Association, 76, 296-311. http://dx.doi.org/10.1080/01621459.1981.10477649

[16] Nawata, K. (2013) A New Estimator of the Box-Cox Transformation Model Using Moment Conditions. Economics Bulletin, 33, 2287-2297.

[17] Hausman, J. (1978) Specification Test in Econometrics. Econometrica, 46, 1251-1272. http://dx.doi.org/10.2307/1913827

[18] Nawata, K. and McAleer, M. (2014) The Maximum Number of Parameters for the Hausman Test When the Estimators Are from Different Sets of Equations. Economics letters, 123, 291-294. http://dx.doi.org/10.1016/j.econlet.2014.03.005

[19] Nawata, K. and Kawabuchi, K. (2015) Financial Sustainability of the Japanese Medical Payment System: Analysis of the Japanese Medical Expenditure for Educational Hospitalization of Patients with Type 2 Diabetes. Health, 7, 10071021. http://dx.doi.org/10.4236/health.2015.78118

[20] Nawata, K. (2015) Robust Estimation Based on the Third-Moment Restriction of the Error Terms for the Box-Cox Transformation Model: An Estimator Consistent under Heteroscedasticity. Economics Bulletin, 3, 1056-1064. 
[21] Nawata, K. and Kawabuchi, K. (2016) Comparison of the Length of Stay and Medical Expenditures among Japanese Hospitals for Type 2 Diabetes Treatments: The Box-Cox Transformation Model under Heteroscedasticity. Health, 8, 49-63. http://dx.doi.org/10.4236/health.2016.81007

[22] Nawata, K. and Kawabuchi, K. (2016) Did the Revision of the Japanese Medical Payment System Work Properly?An Analysis of Averages and Variances of Length of Hospital Stay for Type 2 Diabetes Patients by Individual Hospital. Health, 8, 505-517. http://dx.doi.org/10.4236/health.2016.86054

[23] Innami, I. (2009) Sakaiteki nyuuin no kenkyu (Studies of Social Hospitalization). Toyo Keizai Shinpo Sha, Tokyo. (In Japanese)

[24] Kobato, T., Nakamura, A., Wakiya-Matsumoto, J., et al. (2006) Effects of Implementing Clinical Pathways for Care of Patients Undergoing Ophthalmic Surgery for Cataract, Glaucoma, and Vitreoretinal Disorder. Nippon Ganka Gakkai Zasshi (Japanese Journal of Ophthalmology), 110, 25-30. (In Japanese with English Abstract)

[25] Ministry of Health, Labour and Welfare (2015) Heisei 26 nendo iryou no doukou—Gaisan iryouhi no nendo shuukei kekka )The Trend of Medical Payments in Fiscal Year 2014-Results of Estimated Medical Payments of the Fiscal Year). (In Japanese)

[26] Central Social Insurance Medical Council (2014) Toushin-sho (Heisei 26 nendo shinnryou houshuu kaitei nit suite) (The Report for the Revision of Medical Payments in Fiscal Year 2014). (In Japanese)

[27] Barbieri, V., Schmid, E., Ulmer, H. and Pfeiffer, K.P. (2007) Health Care Supply for Cataract in Austrian Public and Private Hospitals. European Journal of Ophthalmology, 17, 557-564.

\section{Submit or recommend next manuscript to SCIRP and we will provide best service for you:}

Accepting pre-submission inquiries through Email, Facebook, Linkedin, Twitter, etc A wide selection of journals (inclusive of 9 subjects, more than 200 journals)

Providing a 24-hour high-quality service

User-friendly online submission system

Fair and swift peer-review system

Efficient typesetting and proofreading procedure

Display of the result of downloads and visits, as well as the number of cited articles

Maximum dissemination of your research work

Submit your manuscript at: http://papersubmission.scirp.org/ 